\title{
Antipanic Efficacy of Paroxetine and Polymorphism within the Promoter of the Serotonin Transporter Gene
}

\author{
Giampaolo Perna*,', Elisa Favaron', Daniela Di Bella', Riccardo Bussi' and Laura Bellodi' \\ 'Anxiety Disorders Clinical and Research Unit, Istituto Scientifico H.S. Raffaele, Vita-Salute University, Milan, Italy
}

\begin{abstract}
Serotonin selective reuptake inhibitors (SSRIs) are the drugs of choice in the treatment of panic disorder (PD). The serotonin transporter $(5-H T T)$ is a prime target for SSRIs. A functional polymorphism within the promoter region of the 5-HTT gene, leading to different transcriptional efficiency, was repeatedly reported to influence the response to SSRIs in mood disorders while the response of patients with OCD seems unrelated. We tested the hypothesis that allelic variation of the 5-HTT promoter could be related to the antipanic response to paroxetine. In total, 92 patients with PD completed a treatment with a variable dose of paroxetine for 12 weeks. The severity of panic-phobic symptomatology was measured before the beginning of the treatment and after 12 weeks. Allelic variation in each subject was determined using a PCR-based method. Both homozygotes for the long variant (I/I) of the 5-HTT promoter and heterozygotes (I/s) showed a better response to paroxetine than homozygotes for the short variant $(\mathrm{s} / \mathrm{s})\left(\chi^{2}=6.9, p<0.03\right)$. This result emerged in the whole sample, but was related only to female patients $\left(\chi^{2}=7.6, p<0.02\right)$. The presence of the long allelic variant was associated with a better response of panic attacks while was not significantly associated with the response of anticipatory anxiety or phobic avoidance. In conclusion, paroxetine efficacy in PD seems to be related to allelic variation within the promoter of the 5-HTT gene in female subjects. This gender effect might be related to the genomic effects of sex hormones. Understanding the interaction between gender and genes coding for structures target of psychotropic drugs could help to individualize the pharmacological treatment of PD. Neuropsychopharmacology (2005) 30, 2230-2235. doi: I0. 1038/sj.npp. I 300822; published online 20 July 2005
\end{abstract}

Keywords: panic disorder; paroxetine; serotonin; 5-HTTPRL; treatment response

\section{INTRODUCTION}

Epidemiological studies report a lifetime prevalence of panic disorder (PD) between 1.5 and $2.9 \%$ in the general population (Weissman et al, 1997). PD is a chronic and recurrent illness (Wittchen, 1988) that can severely impair the social life and work performance of the people affected. It is associated with a high comorbidity of Mood and Substance Abuse disorders (Lepola et al, 1996) and with a significant incidence of suicide attempts and deaths (Noyes et al, 1991). With the development of effective drugs, no advances in the pharmacological treatment of the disorder have been made in the last 40 years; however, similarly to most of psychiatric disorders, the response to drugs is not homogeneous. There are strong evidences that treatment response is influenced by complex genetic factors and the

\footnotetext{
*Correspondence: Dr G Perna, Department of Neuropsychiatric Sciences, Anxiety Disorders Clinical and Research Unit, Istituto Scientifico H.S. Raffaele, 20 via Stamira d'Ancona, 20127 Milan, Italy, Tel: + 392 2643321 I, Fax: + 39226433265 ,

E-mail: perna.giampaolo@hsr.it

Received 28 September 2004; revised 22 February 2005; accepted 25 April 2005

Online publication: 9 June 2005 at http://www.acnp.org/citations/ Npp06090504046 I/default.pdf
}

possibility to disentangle the role of the major structures modulated by psychotropic medication could help the understanding of why some patients do respond to specific drugs and others do not (Catalano, 2001).

Currently, serotonin selective reuptake inhibitors (SSRIs) are considered the drugs of first choice in the treatment of PD. According to in vitro studies, paroxetine is the most potent inhibitor of serotonin uptake (Hyttel, 1994; Johnson, 1992; Thomas et al, 1987) among available SSRIs.

Serotonin transporter (5-HTT) protein determines the reuptake of serotonin from the intersynaptic cleft, representing the prime target for SSRIs. The human 5-HTT is encoded by a single gene (SLC6A4) on chromosome 17q11.1-q12. A functional polymorphism in the transcriptional control region $1 \mathrm{~kb}$ upstream of the 5-HTT coding sequence has been reported. It consists of a 44 base pair (bp) insertion (long variant) or deletion (short variant) ranging from $\mathrm{bp}-1.212$ to $\mathrm{bp}-1.255$ (Heils et al, 1996). It has been demonstrated that the long $(l)$ and short $(s)$ variants of this 5-HTT gene-linked polymorphic region (5-HTTLPR) had different transcriptional efficiencies. The basal transcriptional activity of the long variant ( $l$ allele) is more than twice that of the short form ( $s$ allele) and differences in 5-HTT mRNA synthesis result in different 5-HTT expression and 5-HT cellular uptake. In vitro studies 
showed that the differences in 5-HTT mRNA synthesis result in different 5-HTT expression and 5-HT cellular uptake (Lesch et al, 1996), thus allowing us to hypothesize that individual differences of clinical response to comparable SSRIs bioavailability could be related to different in vivo expression level of 5-HTT.

Recently, some studies studied the relationship between clinical response to SSRIs and allelic variation within the promoter of the 5-HTT gene. Serotonin reuptake inhibitors are considered the treatment of choice in depressive and obsessive compulsive disorders, but a direct influence of 5-HTTLPR variant seems to be characteristic only of depressive disorders. The response of depressive symptomatology to fluvoxamine (Smeraldi et al, 1998) and paroxetine (Zanardi et al, 2000) was associated to allelic variation within the 5-HTTLPR at equivalent plasma levels. In both studies, antidepressant response was stronger and faster among $1 / 1$ homozygotes compared to heterozygotes and s/s homozygotes. On the contrary, Billett et al (1997) failed to find a relationship between the antiobsessive efficacy and 5-HTTLPR variants while Di Bella et al (2002) found a relationship only in some OCD subtypes. This discordance could be the expression of different biochemical pathways probably subtending or conditioning the efficacy of SSRIs. This idea fits well with differences in dose regimen and in latency of therapeutic effect between these two different disorders (Montgomery, 1994; Tollefson et al, 1994; Greist et al, 1995; Blier and de Montigny, 1998).

The aim of our work is to test the hypothesis that allelic variation of 5-HTT gene expression might be linked to antipanic response to paroxetine and to investigate if this association was related to other clinical or individual characteristics.

Given an analogous response pattern to SSRIs in PD and depressive disorders and given the central role of the serotonergic system in the biological mechanisms underlying PD, we expect to find an influence of 5HTTLPR in the antipanic response similar to that found in major depression.

\section{MATERIALS AND METHODS}

\section{Sample}

A total of 92 outpatients seeking treatment for PD with/ without Agoraphobia concluded a 12-week standardized treatment with paroxetine. Patients were recruited over 12 months at the Anxiety Disorders Clinical and Research Unit of the Department of Neuropsychiatric Sciences, S Raffaele Hospital, Milan. Consensus diagnoses according to DSM IV criteria were established by two senior psychiatrists who independently of each other conducted clinical interviews and the MINI International Neuropsychiatric Interview (Sheehan et al, 1994) to assess the patients. Physical examination and accurate medical history taking were performed to exclude any subjects with lifetime psychiatric diagnoses other than PD, significant somatic or neurologi$\mathrm{cal}$ diseases, and pregnancy. Before beginning treatment with paroxetine, all subjects had to have been off psychotropic medication for at least 2 weeks and not have taken fluoxetine in the 8 weeks prior to entry the study. In total, 20 patients $(22 \%)$ had never taken psychotropic medications, $51(55 \%)$ received low doses of benzodiazepines (equivalent of $5 \mathrm{mg}$ of Diazepam) and 21 (23\%) received both benzodiazepines and antidepressants. None had ever received paroxetine. None of the patients were taking contraceptive pills. All probands were investigated for the presence/absence of a family history for PD assessed according to the Family History (FHRDC) method (Andreasen et al, 1977). Each patient gave their informed consent after receiving a detailed explanation of the study. The procedure of this study was carried out in accordance with the Declaration of Helsinki, 1964 and its amendments (Tokyo, Venice and Hong Kong, 1989). All subjects were all unrelated and of Italian descent.

\section{Drug Treatment}

As previous studies on the effects of SSRIs in PD have shown anxiety to increase during the first days of treatment, especially if the starting doses are too high or raised too fast (Den Boer and Westenberg, 1988; Humble and Wistedt, 1992), we decided to administer paroxetine initially at low doses. The investigators who rated the psychometric scales worked independently of those who managed the drug dosages and both were blind to genotyping. Patients were aware of the treatment they were receiving. At the beginning of treatment, patients took a daily dose of $10 \mathrm{mg}$ for 1 week, followed by $20 \mathrm{mg}$ for the next 3 weeks. The dosage could then be increased by $10 \mathrm{mg} /$ day weekly to a maximum dose of $50 \mathrm{mg} /$ day if the Global Improvement score (range between $1=$ 'very much improved' and $7=$ 'very much worse') on the Clinical Global Impressions scale (CGI) (Guy, 1976) was less than 2 (='much improved') and the side effects were not severe. No concomitant psychotropic drugs or psychotherapeutic interventions of any kind, excluding psycho-educational information, were allowed during the trial.

In order to obtain a more homogeneous sample, plasma levels of paroxetine for the patients were determined between the 9th and the 12th week of treatment (after 2 weeks of stable therapy) by high-performance liquid chromatography as previously described (Lucca et al, 1994). On the same occasion, blood samples for genotyping were also collected. Two patients with paroxetine plasma levels exceeding the mean value of the sample $\pm 1.96 \mathrm{SD}$ were excluded from the study, to avoid extreme differences in the bioavailability of the drug influencing the clinical response (Smeraldi et al, 1998). Genomic DNA was extracted from whole blood of patients. Target DNA was amplified by polymerase chain reaction and detected with a standardize procedure previously described (Deckert et al, 1997). Genotyping was performed blind to the clinical status condition or to the outcome of the drug therapy.

\section{Polymerase Chain Reaction}

DNA was extracted from leukocytes by $\mathrm{NaCl}$ precipitation (Lahiri and Nurnberger, 1991; Miller et al, 1988). Polymerase chain reaction forward primer $5^{\prime}$-GGCGTTGCGC TCTGAATGC- $3^{\prime}$ and reverse primer $5^{\prime}$-GAGGGACTGAG CTGGACACCAC- $3^{\prime}$ were employed.

In total, 35 cycles of $30 \mathrm{~s}$ at $95^{\circ} \mathrm{C}, 30 \mathrm{~s}$ at $61^{\circ} \mathrm{C}$, and $1 \mathrm{~min}$ at $72^{\circ} \mathrm{C}$ were performed. The assay mix contained in a volume 
of $30 \mu \mathrm{l} 50 \mathrm{ng}$ genomic DNA, $2.5 \mathrm{mM}$ dNTPs, $0.1 \mu \mathrm{g}$ of sense and antisense primer, $10 \mathrm{mM}$ Tris- $\mathrm{HCl}(\mathrm{pH} 8.3), 50 \mathrm{mM}$ $\mathrm{KCl}, 1.5 \mathrm{mM} \mathrm{MgCl} 2,5 \%$ dimethyl sulfoxide, and $1 \mathrm{U}$ Taq Polymerase. Polymerase chain reaction products were separated on $3 \%$ agarose gels supplemented with ethidium bromide allowing differentiation of the long (528 bp) and the short ( $484 \mathrm{bp})$ variant.

\section{Clinical Assessment}

Clinical assessment was performed by experienced psychiatrists blind to the drug treatment at days 0 (before the beginning of the study) and week 12, using the following scales:

(a) the Panic Associated Symptoms Scale (PASS) to assess frequency of panic attacks, level of anticipatory anxiety, and phobic avoidance. These yielded a global score (PASS-tot) and subscores for panic attacks (PASS-PA), anticipatory anxiety (PASS-AA), and phobic avoidance (PASS-AV) (Argyle et al, 1991);

(b) the Fear Questionnaire (FQ) produced a global score (FQ-tot) and subscores for agoraphobia (FQ-AGO), blood-injury phobia (FQ-BI) and social phobia (FQSOC)(Marks and Mathews, 1979).

The primary end point of the analysis was the 'good response' defined, quantitatively, as a reduction of at least $50 \%$ from baseline in PASS-tot scores at week 12 and, qualitatively, as a complete disappearance of panic attacks, either complete or limited symptoms attacks during the last week of the study.

The secondary end point was the percentage of decrease of PASS global score ( $\triangle \%$ PASS) from day 0 to week 12 .

We considered also some tertiary end points as

- The absence of panic attacks, either complete or with limited symptoms, (PASS-PA =0) during the last week of the study.

- The absence of anticipatory anxiety (PASS-AA=0) during the last week of the study.
- The absence of phobic avoidance (PASS-AV =0) during the last week of the study. The response of agoraphobic symptoms to paroxetine was also measured by the percentage of decrease of the scores of the FQ-AGO subscale ( $\triangle \% \mathrm{FQ}-\mathrm{AGO})$.

\section{Data Analyses}

Since psychometric scores in our sample were not normally distributed-according to the Shapiro-Wilks test of normality - we decided to use nonparametric testing. Baseline clinical and demographic characteristics of the patients with $\mathrm{PD}$ according to the genotype were compared with the Kruskall-Wallis tests on continuous variables and with $\chi^{2}$ statistics on dichotomous variables. If significant values were obtained, post hoc comparisons ( $\chi^{2}$ and MannWhitney respectively). Bonferroni's correction was applied where appropriate. Statistical analyses have been performed with Statistica package, version 5 .

\section{RESULTS}

Genotype and allelic frequencies, as well as clinical and demographic characteristics of the sample, are shown in Table 1. No significant differences were found among gender and different genotypes. As expected, paroxetine plasma levels did not significantly differ among genotype groups.

The genotypic distribution was not significantly different from the distribution expected according to Hardy-Weinberg equilibrium $\left(\chi^{2}=0.9, p<0.3\right)$.

The pattern of distribution of good responders were significantly different according to sex (males: $28 / 39,72 \%$; females: $\left.25 / 51,49 \% ; \chi^{2}=4.7, p<0.03\right)$. Looking at the specific core phenomena of $\mathrm{PD}$, only the rate of patients with absence of panic attacks after paroxetine treatment was significantly higher $\left(\chi^{2}=5.3, p<0.03\right)$ in males $(27 / 36$, $75 \%)$ than in females $(23 / 46,50 \%)$, while no differences were found for anticipatory anxiety and phobic avoidance. No differences were found for $\Delta \%$ PASS (males $79.7 \pm 23.1$; females $75.1 \pm 27.5)$.

Table I Clinical and Demographic Features of Our Sample According to 5-HTTLPR Variants

\begin{tabular}{|c|c|c|c|c|c|}
\hline & I/I & I/s & $\mathbf{s} / \mathbf{s}$ & 1 & s \\
\hline Number of patients & $19(21.1 \%)$ & $48(53.3 \%)$ & $23(25.6 \%)$ & $86(47.8 \%)$ & $94(52.2 \%)$ \\
\hline Sex (male/female) & $11 / 8$ & $|7 / 3|$ & $11 / 12$ & $39 / 47$ & $39 / 55$ \\
\hline Mean age $\pm S D$ (years) & $33.5 \pm 10.5$ & $34.9 \pm 13.5$ & $33.3 \pm 12.3$ & $34.3 \pm 12.2$ & $34.1 \pm 12.8$ \\
\hline Mean age at onset $\pm S D$ (years) & $26.5 \pm 6.6$ & $28.1 \pm 11.6$ & $25.4 \pm 7.2$ & $27.4 \pm 9.6$ & $26.8 \pm 9.7$ \\
\hline Duration of Illness & $7.0 \pm 8.8$ & $6.7 \pm 7.9$ & $7.9 \pm 7.8$ & $6.8 \pm 8.2$ & $7.3 \pm 7.8$ \\
\hline PASS-global score & $8.5 \pm 4.6$ & $9.8 \pm 4.2$ & $10.3 \pm 5.4$ & $9.2 \pm 4.4$ & $10.0 \pm 4.8$ \\
\hline FQ-global score & $45.7 \pm 26.6$ & $45.9 \pm 24.2$ & $48.2 \pm 23.7$ & $45.8 \pm 24.9$ & $47.0 \pm 23.7$ \\
\hline Mean dosages of paroxetine & $31.1 \pm 7.6$ & $29.6 \pm 8.8$ & $30.6 \pm 8.0$ & $30.1 \pm 8.2$ & $29.9 \pm 8.4$ \\
\hline Blood levels of paroxetine ( $\mathrm{ng} / \mathrm{ml})$ & $44.1 \pm 33.3$ & $43.3 \pm 31.8$ & $47.3 \pm 37.9$ & $43.4 \pm 31.6$ & $45.7 \pm 35.2$ \\
\hline
\end{tabular}


Table 2 Treatment Outcome and 5-HTTLPR Variants in Female Patients with PD

\begin{tabular}{|c|c|c|c|c|c|}
\hline & $\mathbf{I} / \mathbf{I}$ & 1/s & $\mathbf{s} / \mathbf{s}$ & $\mathbf{I}$ & s \\
\hline$\Delta \%$ PASS $*$ & $82.3 \pm 34.3$ & $79.5 \pm 21.9$ & $59.1 \pm 31.6$ & $80.4 \pm 26.0$ & $70.6 \pm 27.9$ \\
\hline Good Responders* & $6 / 8(75 \%)$ & $|7 / 3|(55 \%)$ & $2 / 12(17 \%)$ & $29 / 47$ (62\%) & $21 / 55(38 \%)$ \\
\hline No panic attacks at week 12* & $6 / 7(86 \%)$ & $16 / 30(53 \%)$ & 1/9 (11\%) & $28 / 44(64 \%)$ & I8/48 (38\%) \\
\hline No anticipatory anxiety at week 12 & $5 / 8(63 \%)$ & $12 / 29(4 \mid \%)$ & $2 / 12(17 \%)$ & $22 / 45(49 \%)$ & 16/53 (30\%) \\
\hline No agoraphobia at week 12 & $5 / 6(83 \%)$ & 13/22 (59\%) & $7 / 11(64 \%)$ & $23 / 34(68 \%)$ & $27 / 44(61 \%)$ \\
\hline
\end{tabular}

$* p<0.05$.

Table 3 Treatment Outcome and 5-HTTLPR Variants in Male Patients with PD

\begin{tabular}{|c|c|c|c|c|c|}
\hline & I/I & I/s & $\mathbf{s} / \mathbf{s}$ & $\mathbf{I}$ & s \\
\hline$\Delta \%$ PASS & $83.5 \pm 30.8$ & $80.5 \pm 20.3$ & $64.7 \pm 28.0$ & $83.5 \pm 24.3$ & $75.9 \pm 21.1$ \\
\hline Good responders & $9 / 11(82 \%)$ & $12 / 17(71 \%)$ & $7 / 11$ (64\%) & $30 / 39(77 \%)$ & $26 / 39(67 \%)$ \\
\hline No panic attacks at week 12 & $10 / 1 \mid(91 \%)$ & $11 / 16(69 \%)$ & $7 / 10$ (70\%) & $31 / 38(82 \%)$ & $25 / 36(69 \%)$ \\
\hline No anticipatory anxiety at week 12 & $5 / 10(50 \%)$ & $6 / 16(37 \%)$ & $2 / 11(18 \%)$ & $16 / 36(44 \%)$ & $10 / 38(26 \%)$ \\
\hline No agoraphobia at week 12 & $7 / 8(87 \%)$ & $10 / 15(67 \%)$ & $5 / 10(50 \%)$ & $24 / 31(77 \%)$ & $20 / 35(57 \%)$ \\
\hline
\end{tabular}

Statistical analysis showed a significant difference of the clinical response to paroxetine, both measured quantitatively and qualitatively in the whole sample, according to genotypes $\left(\chi^{2}=6.9, p<0.03\right)$. Analysing this difference according to sex, this result was confirmed only in the female subsample (Tables 2 and 3). Only among female patients there was a significant association between good response and genotypic $\left(\chi^{2}=7.6, p<0.02\right)$ or allelic $\left(\chi^{2}=5.6, p<0.02\right)$ variants while no significant effect was found in males. Post hoc analyses showed that good responders were significantly more frequent among 11 and $1 / \mathrm{s}$ female patients than those with s/s one (1/l vs s/s: $\chi^{2}=7.6$, $p<0.02 ; 1 / \mathrm{s}$ vs s/s: $\chi^{2}=5.1, p<0.02 ; 1 / 1$ vs $1 / \mathrm{s}$ : NS).

As well, Kruskal-Wallis test showed a significant 5HTTPRL genotype effect on $\Delta \%$ PASS $(H=10.939$, $p<0.004)$ and also this result was supported by the female group $(H=7.3, p<0.03)$. Post hoc comparisons showed that PASS global score decreased lesser in s/s female patients than in $1 / 1$ and $1 / \mathrm{s}$ female patients that did not differ eachother $(1 / 1$ vs s/s: $Z=3.0, p<0.002 ; 1 / \mathrm{s}$ vs s/s: $Z=3.1$, $p<0.002 ; 1 / 1$ vs $1 / \mathrm{s}$ : NS).

Mann-Whitney test showed that a stronger decrease of PASS global scores was significantly associated with 1 allelic variant $(Z=2.4, p<0.02)$ only in females.

Looking at the specific core phenomena of $\mathrm{PD}$, in female patients genotypic and allelic variants were associated with the response to paroxetine for panic attacks but not for anticipatory anxiety or for phobic avoidance. $\chi^{2}$ analyses showed a significant association $\left(\chi^{2}=9.1, p<0.01\right)$ between the absence of panic attacks after paroxetine treatment and genotypic distribution. Post hoc analyses showed that the absence of panic attacks was significantly more frequent among homozygotic patients with $1 / 1$ genotype than those heterozygotic and homozygotic with s/s genotype. No panic attacks after paroxetine treatment were also significantly $\left(\chi^{2}=6.3, p<0.02\right)$ more associated with 1 allelic variant. No significant differences were found between genotypic or allelic variant distribution and absence of anticipatory anxiety or agoraphobic avoidance at the end of paroxetine treatment. Kruskal-Wallis test also showed no significant 5-HTTLPR genotype effect on $\triangle \%$ FQ-AGO scores (1/1: $64.4 \pm 38.6 ; 1 / s: 40.3 \pm 62.8$; s/s: $62.7 \pm 40.7)$. Similar results were found for allelic variants (1: $48.0 \pm 56.2$; s: $50.0 \pm 54.4$ ).

\section{DISCUSSION}

Our results provide the first experimental evidence that allelic variation of 5-HTTLPR influences the response to SSRIs at equal bioavailability in PD, supporting the idea that the availability of 5-HT transporter is important for a clinically useful antipanic effect. We can summarize the results of our study as follows: (1) Clinical antipanic effectiveness of paroxetine seems to be related to the allelic variations of the 5-HTTLPR specifically in female patients; (2) among the core features of $\mathrm{PD}$, the treatment outcomegenotype relationship seems to be related selectively to panic attacks while anticipatory and phobic avoidance seem to be less influenced. These findings are not explained by differences either in clinical and demographical features of the sample or to paroxetine plasma levels.

The finding that the $s$ genotype specifically affects the antipanic properties of paroxetine, and not the more general antianxiety effect, is in line with evidences about overlapping but separate serotonergic pathways underlying panic and anxiety, well expressed in the 'Deakin-Graeff model' (Graeff, 2004).

The finding that the genetic-clinical response association depends on female gender, never previously reported to our knowledge, is interesting. Growing evidences support the existence of gender differences related to the function of the serotonergic system and the 5-HTT gene. There are 
evidences of gender differences in the effects of the 5HTTLPR polymorphism variants on cerebrospinal fluid levels of 5-hydroxyindoleacetic acid (5-HIAA), an index of serotonergic turnover. Healthy females with the s/s genotype had higher 5-HIAA levels in the cerebrospinal fluid than males (Williams et al, 2003).

Female 5-HTT knockout mice show a prominent increase in anxiety and stress response than male mice (Wichems et al, 2000; Li et al, 2000).

The effect of estrogen on decreasing the transporter expression could play a more important role on the s/s genotype, already characterized by low 5-HTT expression. Finally, we cannot forget the growing evidences of a SSRIsneurosteroids link (Griffin and Mellon, 1999). Recent studies suggest the existence of a relationship between panic attacks induced by sodium lactate or cholecystokinin tetrapeptide and neurosteroids (Strohle et al, 2003), as well as we have recently shown an association between PD and neurosteroids (Brambilla et al, 2003). Possible genomic influences of neuroactive steroids (Van Broekhoven and Verkes, 2003) on 5-HT transporter may be relevant for the association found.

The treatment outcome-5 HTTPRL association found in female patients seems to be related only to panic attacks while the same is not present for anticipatory anxiety and phobic avoidance. This observation is in line with the consistent evidences of significant influences of sex hormones-related conditions on panic attacks.

We have previously reported that carbon dioxide-induced panic attacks are influenced by menstrual cycle phases: during the luteal phase, when progesterone blood levels are higher, females seem to be protected against panic attacks (Perna et al, 1995). Many studies reported that $\mathrm{PD}$ is exacerbated in the premenstrual period and in postpartum, with lactation being apparently protective as well as pregnancy: the correlation of premenstrual dysphoria with postpartum symptomatology suggests progesterone withdrawal as a common mechanism (Klein, 1993). In addition, some case reports showed that oral contraceptives and estrogen replacement therapy were able to trigger panic attacks (Price and Heil, 1988; Deci et al, 1992).

Panic attacks might be the specific PD feature whose clinical response is influenced by the allelic variation of functional 5-HTTLPR and its interaction with sex steroidal hormones.

In conclusion, our results support the hypothesis that the therapeutic response to antipanic drugs modulating the 5HTT may be influenced by 5-HTTLPR, however, suggesting that this association is valid only for females.

Our results should be considered cautiously since only replications in independent samples, using placebo-control group and different serotonergic compounds, could give us a definitive answer. In particular if a similar pattern of response is present in a placebo-control group, we can think that the s genotype effect might be mainly related to aspecific psychological factors, enhancing the 'placebo effect', rather than to specific antipanic effects.

In addition, we cannot exclude that our finding might be linked to undetected population stratification and, given the small sample size, a type II error cannot be excluded. Type II error could in particular affect the negative finding referring to the association between clinical antipanic response and 5-HTTLPR in males.

Moreover, although we ensured that plasma paroxetine levels did not differ, since we did not measure the side effects, we cannot exclude that the influence of s genotype could have been mediated via a differential impact of the $s$ genotype on side effects frequency or intensity.

Another limitation of the study is the number of polymorphisms examined: we know that the small effect of 5HTT gene dampens the meaning of the study. To overcome this issue, future studies will have to consider also the effect of other genes involved in the serotonergic pathway, such as MAO-A or serotonin receptor $1 \mathrm{~A}$.

Finally, a detailed assessment of variables related to sex hormones system (ie phase of the menstrual cycle) could help to better understand our findings.

$\mathrm{PD}$ is a complex disease and the response of its different core features to drug treatments might vary for both genetic (functional 5-HTTLPR) and environmental factors (sex steroidal hormones). The results of our study should encourage the investigation of the influence of other polymorphic genes on the clinical response to antipanic medications and the possible role of sex hormones, in particular neurosteroids, in modulating genetic regulation of neurotransmitters.

\section{ACKNOWLEDGEMENTS}

We thank Ernestina Politi, MD, Caldirola Daniela, MD, Giovanna Vanni, MD, and Angelo Bertani, MD for data collection.

\section{REFERENCES}

Andreasen NC, Endicott J, Spitzer RL, Winokur G (1977). The family history method using diagnostic criteria. Reliability and validity. Arch Gen Psychiatry 34: 1229-1235.

Argyle N, Deltito J, Allerup P, Mayer W, Albus M, Nutzinger D et al (1991). The panic-associated symptom scale: measuring the severity of panic disorder. Acta Psychiatr Scand 83: 20-26.

Billett EA, Richter MA, King N, Heils A, Lesch KP, Kennedy JL (1997). Obsessive compulsive disorder, response to serotonin reuptake inhibitors and the serotonin transporter gene. Mol Psychiatry 2: 403-406.

Blier P, de Montigny C (1998). Possible serotonergic mechanisms underlying the antidepressant and anti-obsessive-compulsive disorder responses. Biol Psychiatry 44: 313-323.

Brambilla F, Biggio G, Pisu M, Bellodi L, Perna G, BogdanovicDjukic V (2003). Neurosteroid secretion in panic disorder. Psychiatry Res 118: 107-116.

Catalano M (2001). Functionally gene-linked polymorphic regions and genetically controlled neurotransmitters metabolism. Eur Neuropsychopharmacol 11: 431-439.

Deci PA, Lydiard RB, Santos AB, Arana GW (1992). Oral contraceptives and panic disorder. J Clin Psychiatry 53: 163-165.

Deckert J, Catalano M, Heils A, Di Bella D, Friess F, Politi E et al (1997). Functional promoter polymorphism of the human serotonin transporter: lack of association with panic disorder. Psychiatr Genet 7: 45-47.

Den Boer JA, Westenberg HG (1988). Effect of a serotonin and noradrenaline uptake inhibitor in panic disorder; a double-blind comparative study with fluvoxamine and maprotiline. Int Clin Psychopharmacol 3: 59-74. 
Di Bella D, Erzegovesi S, Cavallini MC, Bellodi L (2002). Obsessivecompulsive disorder, 5-HTTLPR polymorphism and treatment response. Pharmacogenomics J 2: 176-181.

Graeff FG (2004). Serotonin, the periaqueductal gray and panic. Neurosci Biobehav Rev 28: 239-259.

Greist J, Chouinard G, DuBoff E, Halaris A, Kim SW, Koran L et al (1995). Double-blind parallel comparison of three dosages of sertraline and placebo in outpatients with obsessive-compulsive disorder. Arch Gen Psychiatry 52: 289-295.

Griffin LD, Mellon SH (1999). Selective serotonin reuptake inhibitors directly alter activity of neurosteroidogenic enzymes. Proc Natl Acad Sci USA 96: 13512-13517.

Guy W (ed) (1976). Clinical global impressions. In: ECDEU Assessment Manual for Psychopharmacology, revised. US National Institute of Mental Health, Psychopharmacology Research Branch: Rockville, MD. pp 217-222.

Heils A, Teufel A, Stober G, Riederer P, Bengel D, Lesch K (1996). Allelic variation of human serotonin transporter gene expression. J Neurochem 66: 2621-2624.

Humble M, Wistedt B (1992). Serotonin, panic disorder and agoraphobia: short-term and long-term efficacy of citalopram in panic disorders. Int Clin Psychopharmacol 6(Suppl 5): 21-39.

Hyttel J (1994). Pharmacological characterization of selective serotonin reuptake inhibitors (SSRIs). Int Clin Psychopharmacol 9(Suppl 1): 19-26.

Johnson AI (1992). Paroxetine: a pharmacological review. Int Clin Psychopharmacol 6: 15-24.

Klein DF (1993). False suffocation alarms, spontaneous panics, and related conditions. An integrative hypothesis. Arch Gen Psychiatry 50: 306-317.

Lahiri D, Nurnberger J (1991). A rapid non enzymatic method for the preparation of HMW DNA from blood for RFLP studies. Nucleic Acid Res 19: 5444.

Lepola U, Koponen H, Leinonen E (1996). A naturalistic 6-year follow-up study of patients with panic disorder. Acta Psychiatr Scand 93: 181-183.

Lesch K, Bengel D, Heils A, Sabol SZ, Greenberg BD, Petri S et al (1996). Association of anxiety-related traits with a polymorphism in the serotonin transporter gene regulatory region. Science 274: 1527-1531.

Li Q, Wichems C, Heils A, Lesch KP, Murphy DL (2000). Reduction in the density and expression, but not G-protein coupling, of serotonin receptors (5-HT1A) in 5-HT transporter knock-out mice: gender and brain region differences. J Neurosci 20: 7888-7895.

Lucca A, Lucini V, Catalano M, Alfano M, Smeraldi E (1994). Plasma tryptophan to large neutral amino acids ratio and therapeutic response to a selective serotonin uptake inhibitor. Neuropsychobiology 29: 108-111.

Marks I, Mathews A (1979). Brief standard self-rating for phobic patients. Behav Res Ther 17: 263-267.

Miller SA, Dykes DD, Polesky HF (1988). A simple salting out procedure for extracting DNA from human nucleated cells. Nucleic Acids Res 16: 1215.
Montgomery SA (1994). Pharmacological treatment of obsessivecompulsive disorder. In: Hollander EZJ, Marazziti D, Olivier B (eds). Current Insights in Obsessive Disorder. Wiley: New York. pp 215-226.

Noyes Jr R, Christiansen J, Clancy J, Garvey MJ, Suelzer M, Anderson DJ (1991). Predictors of serious suicide attempts among patients with panic disorder. Comp Psychiatry 32: 261-267.

Perna G, Brambilla F, Arancio C, Bellodi L (1995). Menstrual cyclerelated sensitivity to $35 \% \mathrm{CO} 2$ in panic patients. Biol Psychiatry 37: 528-532.

Price WA, Heil D (1988). Estrogen-induced panic attacks. Psychosomatics 29: 433-435.

Sheehan DV, Lecrubier Y, Weiller E, Hergueta T, Janavs J (1994). Mini International Neuropsychiatric Interview, MINI, Paris/ Tampa.

Smeraldi E, Zanardi R, Benedetti F, Di Bella D, Perez J, Catalano M (1998). Polymorphism within the promoter of the serotonin transporter gene and antidepressant efficacy of fluvoxamine. Mol Psychiatry 3: 508-511.

Strohle A, Romeo E, di Michele F, Pasini A, Hermann B, Gajewsky $\mathrm{G}$ et al (2003). Induced panic attacks shift gamma-aminobutyric acid type A receptor modulatory neuroactive steroid composition in patients with panic disorder: preliminary results. Arch Gen Psychiatry 60: 161-168.

Thomas D, Nelson D, Johnson AI (1987). Biochemical effects off the antidepressant paroxetine, a specific 5-hydroxytriptamine uptake inhibitor. Psychopharmacology 93: 193-200.

Tollefson GD, Rampey Jr AH, Potvin JH, Jenike MA, Rush AJ, Kominguez RA et al (1994). A multicenter investigation of fixeddose fluoxetine in the treatment of obsessive-compulsive disorder. Arch Gen Psychiatry 51: 559-567.

Van Broekhoven F, Verkes RJ (2003). Neurosteroids in depression: a review. Psychopharmacology (Berl) 165: 97-110.

Weissman MM, Bland RC, Canino GJ, Faravelli C, Greenwald S, Hwu HG et al (1997). The cross-national epidemiology of panic disorder. Arch Gen Psychiatry 54: 305-309.

Wichems C, Li Q, Andrews A, Lesch K, Murphy D (2000). Serotonin transporter knock-out mice show a spontaneous behavioral phenotype of increased 'anxiety' and stress responses. Int J Neuropsychopharmacol 3: S47.

Williams RB, Marchuk DA, Gadde KM, Barefoot JC, Grichnik K, Helms MJ et al (2003). Serotonin-related gene polymorphisms and central nervous system serotonin function. Neuropsychopharmacology 28: 533-541.

Wittchen H (1988). Natural course and spontaneous remissions of untreated anxiety disorders: results of the Munich Follow-up Study. In: Hand I WH (ed). Panic and Phobias: Treatments and Variables Affecting Course and Outcome. Springer Verlag: New York. pp 3-17.

Zanardi R, Benedetti F, Di Bella D, Catalano M, Smeraldi E (2000). Efficacy of paroxetine in depression is influenced by a functional polymorphism within the promoter of the serotonin transporter gene. J Clin Psychopharmacol 20: 105-107. 